\title{
Immune Reconstitution in Pediatric Patients Following Hematopoietic Cell Transplant for Non-malignant Disorders
}

\author{
Sima T. Bhatt and Jeffrey J. Bednarski*t \\ Department of Pediatrics, Washington University School of Medicine in St. Louis, St. Louis, MO, United States
}

Allogeneic hematopoietic cell transplant $(\mathrm{HCT})$ is curative for pediatric patients with non-malignant hematopoietic disorders, including hemoglobinopathies, bone marrow failure syndromes, and primary immunodeficiencies. Early establishment of donorderived innate and adaptive immunity following HCT is associated with improved overall survival, lower risk of infections and decreased incidence of graft failure. Immune reconstitution (IR) is impacted by numerous clinical variables including primary disease,

OPEN ACCESS

Edited by:

Kirk R. Schultz,

The University of British Columbia,

Canada

Reviewed by:

Mahzad Akbarpour

Northwestern University Feinberg School of Medicine, United States

Ying-Jun Chang,

Peking University People's Hospital,

China

*Correspondence:

Jeffrey J. Bednarsk

bednarski_@wustl.edu

TORCID:

Jeffrey J. Bednarski orcid.org/0000-0001-6902-0876

Specialty section:

This article was submitted to Alloimmunity and Transplantation,

a section of the journal

Frontiers in Immunology

Received: 29 May 2020

Accepted: 23 July 2020

Published: 18 August 2020

Citation:

Bhatt ST and Bednarski JJ (2020) Immune Reconstitution in Pediatric Patients Following Hematopoietic Cell

Transplant for Non-malignant

Disorders. Front. Immunol. 11:1988.

doi: 10.3389/fimmu.2020.01988 donor characteristics, conditioning regimen, and graft versus host disease (GVHD). Recent advancements in HCT have been directed at reducing toxicity of conditioning therapy, expanding donor availability through use of alternative donor sources, and addressing morbidity from GVHD with novel graft manipulation. These novel transplant approaches impact the kinetics of immune recovery, which influence post-transplant outcomes. Here we review immune reconstitution in pediatric patients undergoing HCT for non-malignant disorders. We explore the transplant-associated factors that influence immunologic recovery and the disease-specific associations between IR and transplant outcomes.

Keywords: immune reconstitution, hematopoietic stem cell transplant, non-malignant disorders, hemoglobinopathy, severe combined immunodeficiency, aplastic anemia

\section{INTRODUCTION}

Allogeneic hematopoietic cell transplant (HCT) is a key therapeutic approach for many non-malignant hematopoietic diseases in pediatric patients, including hemoglobinopathies, bone marrow failure syndromes, and immunodeficiencies. Effective reconstitution of donorderived innate and adaptive immune cell number and function following HCT is critical for promoting donor cell engraftment, restoring protection against infections, and improving overall survival $(1,2)$.

Recovery of immunity after HCT is influenced by various clinical factors, including primary diagnosis, donor type, stem cell source, graft manipulation, conditioning regimen (i.e., intensity of conditioning, use of irradiation, serotherapy), and pharmacologic prophylaxis, development and treatment of graft-versus-host disease (GVHD) $(1,2)$. After HCT, establishment of donor immunity is variable and occurs in phases. Innate immune reconstitution (IR) occurs first with

Abbreviations: ATG, anti-thymocyte globulin; BM, bone marrow; CMV, cytomegalovirus; GVHD, graft-versus-host disease; HCT, hematopoietic cell transplant; IR, immune reconstitution; MAC, myeloablative conditioning; MRD, matched related donor; MSD, matched sibling donor; NK, natural killer; $\mathrm{PB}$, peripheral blood; RD, related donor; RIC, reduced intensity conditioning; RTC, reduced toxicity conditioning; UCB, umbilical cord blood; URD, unrelated donor. 
neutrophils, monocytes, natural killer (NK) cells, and dendritic cells expected to normalize in the first weeks to month after HCT (1). Adaptive immune system recovery occurs more slowly with $\mathrm{B}$ cell and CD8 $\mathrm{T}$ cell numbers normalizing between 100 days and 6 months post HCT and thymic-dependent CD4 $\mathrm{T}$ cell reconstitution occurring between 6 and 9 months (1). Initial $\mathrm{T}$ cell reconstitution occurs through peripheral expansion of CD8 memory $\mathrm{T}$ cells from the donor graft or recipient $\mathrm{T}$ cells remaining after conditioning (3). These peripherally expanded CD8 $\mathrm{T}$ cells are responsive to cytokines and previously encountered viruses; however, they have limited ability to respond to novel antigens (3). The second phase, leading to full $\mathrm{T}$ cell reconstitution, relies on lymphoid progenitors undergoing thymic differentiation into naive $\mathrm{CD} 4$ or $\mathrm{CD} 8 \mathrm{~T}$ cells expressing MHC-restricted, antigen-specific $\mathrm{T}$ cell receptors (3). The kinetics of reconstitution of these distinct components of the immune system correlate with post-transplant morbidity related to infections, graft loss and GVHD. Here we review the factors that influence recovery of innate and adaptive immunity in pediatric patients undergoing HCT for non-malignant disorders and the impact of this reconstitution on general and diseasespecific outcomes.

\section{TRANSPLANT-ASSOCIATED FACTORS AFFECTING IMMUNE RECONSTITUTION}

\section{Stem Cell Source}

Peripheral blood (PB), bone marrow (BM), or umbilical cord blood (UCB) stem cells can be utilized for HCT from either related (RD) or unrelated donors (URD). These donor sources vary in cellular composition with $\mathrm{PB}$ grafts having 10 -fold higher $\mathrm{T}$ and $\mathrm{B}$ cells than $\mathrm{BM}$ grafts and single UCB grafts having 10-100-fold fewer nucleated cells compared to BM (1, $4,5)$. The differences in graft composition impact donor IR and infectious complications following HCT. Regarding innate immunity, neutrophil engraftment occurs at approximately 14 , 21 , and 30 days after a PB, BM, and UCB HCT, respectively (6). Interestingly, NK cell numbers normalize by 1 month post HCT independent of graft source (6). Yet, UCB recipients have been found to have higher numbers of NK cells at 3, 9, and 12 months after transplant (7).

Graft source also impacts reconstitution of adaptive immunity. HCT with UCB has been associated with higher naive and memory B cell numbers at 6 months post HCT compared to $\mathrm{BM}$ and $\mathrm{PB}$ grafts (8). In contrast, $\mathrm{T}$ cell reconstitution is delayed after UCB HCT (7-9). UCB contains antigen-inexperienced naive $\mathrm{T}$ cells; therefore, $\mathrm{T}$ cell recovery is entirely thymic dependent resulting in profound early lymphopenia $(7,10,11)$. Recipients of UCB HCTs have a slower recovery of thymopoiesis than patients receiving $\mathrm{BM}$ stem cells as evidenced by a lower thymic-derived naive CD4 T cells at 6 months post HCT (7).

$\mathrm{T}$ cell reconstitution also differs between $\mathrm{BM}$ and $\mathrm{PB}$ recipients. In a single institution randomized trial, patients who received PB grafts had faster lymphocyte recovery, most significantly CD4 T cells, compared to BM graft recipients (4). Consistent with slower IR, BM stem cell recipients had a 2.4-fold higher rate of severe infections and a higher risk of infectionrelated mortality (4). A larger, phase 3 trial confirmed earlier IR and lower infection risk in patients receiving PB grafts but did not identify any differences in mortality (12). Thus, donor IR after HCT is highly impacted by distinct properties of the different stem cell sources (Figure 1).

\section{Alternative Donor Sources}

While an HLA matched donor is preferred, less than 25\% of patients will have an available sibling donor and the likelihood of identifying a matched URD in the registry is impacted by numerous factors, including ethnicity of the patient (13). Consequently, alternative donors have been increasingly used for HCT with unique implications for post-HCT IR (Figure 1).

UCB has been utilized as an alternative donor source and has distinctive IR properties as discussed above. However, there are significant barriers to success of UCB transplants, including graft failure and delayed neutrophil and T cell recovery, resulting in infectious complications $(10,11,14)$. Addressing these obstacles has been an active area of investigation (6, 10, 15). UCB has lower total nucleated cell and CD34 + cell dose (per recipient's weight), which has been associated with delayed hematological recovery and graft failure (11). Strategies to improve cell dose for UCB have included double cord blood transplant and ex vivo expansion of cord blood units. While IR data on double UCB HCT is limited in pediatrics, in adults, it has not consistently demonstrated an improvement in IR compared to single UCB HCT $(10,16,17)$. This may be, in part, related to confounding factors, including the use of $\mathrm{T}$ cell depletion (10). Further studies are needed to better address this question. In contrast, recent early phase clinical trials using ex vivo cord blood expansion have demonstrated that neutrophil engraftment can be shorted to 9 days from 21 days $(15,18)$. In regard to $\mathrm{T}$ cell recovery, lower doses of anti-thymocyte globulin (ATG) have been associated with faster recovery of CD4 and CD8 T cells after UCB transplant (14, 19, 20). Additionally, use of better HLA-matched cord blood units with higher $\mathrm{CD} 3 \mathrm{~T}$ cell counts has been shown to improve immune recovery (21).

The use of haploidentical donors as an acceptable alternative stem cell source has surged with recent studies aimed to reduce the risk of GVHD, sustain donor engraftment, and support earlier IR $(13,22)$. The kinetics of IR following haploidentical donor HCT depends on conditioning regimen, stem cell source, and graft manipulation strategy utilized. For example, time to neutrophil engraftment varies from a median of 11-12 days after $\mathrm{T}$ cell depletion with high dose $\mathrm{CD} 34$ + cells to 13 days after GCSF-mobilized haploidentical unmanipulated PB graft to 15 days after unmanipulated haploidentical BM (23). Similar to HLA-matched transplant, monocyte and NK cell recovery is rapid and occurs by day 15 and 30, respectively, after haploidentical HCT (23). Regarding adaptive immunity, patients receiving $\mathrm{T}$ cell replete haploidentical grafts have more rapid $\mathrm{T}$ cell IR during the first 6 months after HCT compared to patients who received $\mathrm{T}$ cell-depleted grafts (23). $\mathrm{T}$ cell function and new naive $\mathrm{T}$ cell production remain low for 12-24 months after unmanipulated haploidentical HCT (23). 


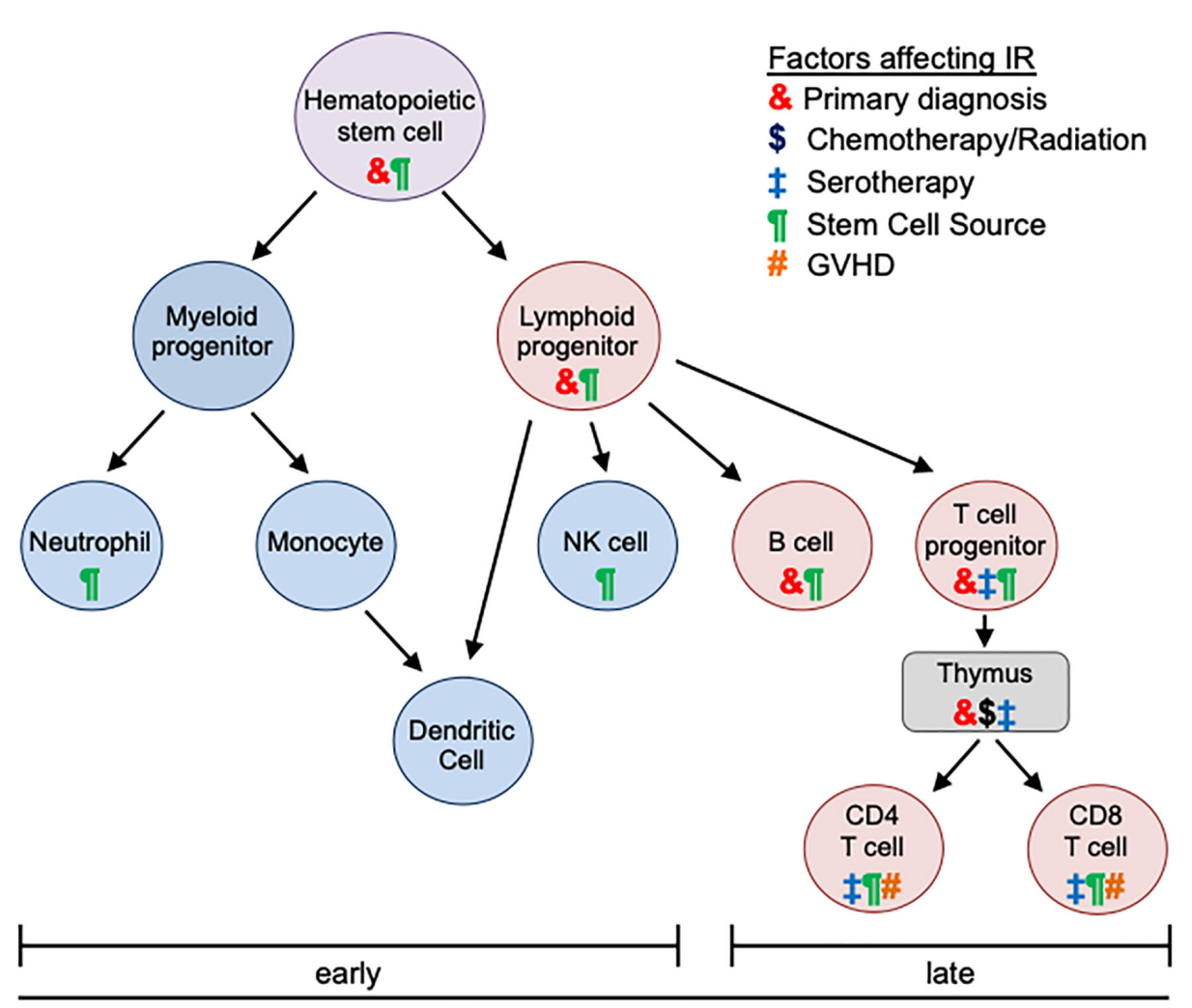

Time post-transplant

FIGURE 1 | Effects of transplant-related factors on immune reconstitution. Different types of immune cells and their differentiation are depicted. After allogeneic HCT innate immunity (blue) recovers early (within 30 days). Reconstitution of adaptive immunity (red) is later and more variable (often up to 1 year). The kinetics of immune recovery is influenced by primary diagnosis (\&), conditioning regimen (\$), use of serotherapy (¥), stem cell source (ף), and GVHD (\#). Each transplant-associated factor distinctly impacts different immune populations and differentiation stages.

Due to delayed recovery of adaptive immunity and associated infection risks, strategies for ex vivo elimination of $\alpha \beta \mathrm{T}$ cells and CD19 B cells with no pharmacologic prophylaxis for GVHD has been utilized for haploidentical transplant in patients with non-malignant disorders $(13,22)$. In a study of 23 patients, $\gamma \delta \mathrm{T}$ cell recovery occurred early $(\sim 1$ month post HCT), but $\alpha \beta \mathrm{T}$ cell and CD19 B cell repopulation was delayed to 912 months, respectively (13). Alternative donor sources are often used in patients with non-malignant disorders who have no available familial or registry donor. Improving IR in this patient population remains an active area of investigation.

\section{Conditioning Strategies}

IR is also impacted by conditioning regimen, including intensity of chemotherapy, use of radiation, and use of serotherapy (Figure 1). In particular, conditioning therapy can damage the thymus and impair its function, which is essential for full T cell reconstitution. For example, cyclophosphamide and radiation induce acute thymic injury with loss of cellularity whereas ATG and alemtuzumab serotherapy significantly deplete thymocytes resulting in prolonged $\mathrm{T}$ cell aplasia (3).

Patients with non-malignant disorders often receive reduced toxicity (RTC) and reduced intensity conditioning (RIC) regimens in order to limit the morbidity associated with myeloablative conditioning (MAC). RIC regimens are nonmyeloablative while RTC regimens are myeloablative. Both approaches have fewer side effects and organ toxicities compared to traditional MAC. Law et al. reported that following a RTC regimen of alemtuzumab, busulfan, and fludarabine median time to neutrophil recovery was 16 days while time to B cell and $\mathrm{T}$ cell reconstitution was 3 and 6 months, respectively (24). A RIC approach with alemtuzumab, fludarabine and melphalan has been used by our group and others (25$28)$. We recently reported IR and infectious complications in patients after HCT with early alemtuzumab (day -21) (26). NK cell recovery was rapid by day 100 and lymphocyte recovery was dependent on donor source, namely related (RD) versus unrelated donor (URD). Mean CD3, CD4, and CD8 T cell numbers normalized by 6 months after RD HCT and by 1 year in the URD group (26). B cell recovery occurred by day 100 for $\mathrm{RD}$ recipients and by 1 year for URD recipients (26). Despite these differences, infections did not differ between the groups (26).

Timing and dose of serotherapy significantly impact IR (20, 29, 30). Admiraal et al. reported on IR in patients with malignant and non-malignant disorders receiving ATG as part of conditioning 
(20). They found that successful CD4 IR was related to the area under the curve (AUC) of ATG after donor stem cell infusion (20). Patients who received UCB HCT had delayed IR with an $\mathrm{AUC} \geq 20 \mathrm{AU} \times$ day $/ \mathrm{mL}$ while patients who received $\mathrm{BM}$ and PB HCT had decreased IR only at an AUC $\geq 100 \mathrm{AU} \times$ day/mL (20). Notably, an ATG AUC $\geq 40 \mathrm{AU} \times$ day/mL prior to stem cell infusion resulted in a lower incidence of graft failure and acute and chronic GVHD (20). Marsh et al. similarly demonstrated that alemtuzumab level at time of transplant impacts outcomes (30). They found patients with a level $<0.15 \mathrm{mg} / \mathrm{mL}$ had threefold higher rates of acute GVHD than patients who had levels $>0.16 \mathrm{mg} / \mathrm{mL}$ at the time of transplant. Alemtuzumab levels above $0.57 \mathrm{mg} / \mathrm{mL}$ were associated with delayed $\mathrm{T}$ cell recovery and very high levels $(4 \mathrm{mg} / \mathrm{mL})$ were associated with mixed chimerism (30). The approach to conditioning is often dictated by primary disease/graft source and requires careful consideration to balance IR with risks of GVHD and graft failure.

\section{DISEASE-SPECIFIC OUTCOMES}

\section{Hemoglobinopathies}

HCT for pediatric patients with thalassemia and sickle cell disease is potentially curative and the impact of IR on transplantassociated morbidity and outcome has been investigated by several groups. Rajasekar et al. detailed IR patterns in patients with $\beta$ thalassemia major following MAC and matched related donor (MRD) HCT with BM graft (31). They found that NK cells, monocytes and dendritic cells recovered within 1 month of transplant (31). CD8 $\mathrm{T}$ cells and $\mathrm{B}$ cells repopulated at 2 and 4 months, respectively, while CD4 $\mathrm{T}$ cell recovery did not occur by 1 year post HCT (31). Consistent with this, naive CD4 $\mathrm{T}$ cell $\left(\mathrm{CD} 45 \mathrm{RA}^{+}\right)$recovery was delayed more than a year and correlated with age, with younger patients having faster recovery (31). Interestingly, multivariate analysis showed that NK cell count correlated with transplant success as patients with NK cells below a median of $142 / \mu \mathrm{L}$ at 28 days post HCT had a significantly higher rejection rate and lower event free survival (31).

In order to prevent graft failure/rejection, in vivo $\mathrm{T}$ cell depletion is increasingly utilized in patients with hemoglobinopathies (32). An evaluation of IR in children with severe $\beta$ thalassemia major following matched sibling donor (MSD) HCT found that the addition of ATG led to delayed CD8 $\mathrm{T}$ cell recovery at 6 months but no change in CD4 T cell reconstitution, which occurred at 12 months (33). Use of ATG containing conditioning regimens was associated with variable rates of bacterial infection (17-70\%) and cytomegalovirus (CMV) reactivation $(36-45 \%)(32,33)$. These infectious complications are similar to those in patients transplanted without in vivo $\mathrm{T}$ cell depletion (32). However, rates of GVHD were lower after ATG-based conditioning (32).

Our group has reported similar outcomes in patients with hemoglobinopathies undergoing $\mathrm{HCT}$ with in vivo $\mathrm{T}$ cell depletion utilizing alemtuzumab (34). Lymphocyte recovery of CD4, CD8, and CD19 occurred by 1 year post transplant and was impacted by duration and intensity of immunosuppression for GVHD prophylaxis/treatment (34). Infection risk was highest in the first 6 months post HCT with bacterial infections and CMV reactivation in 28 and $43 \%$ of patients, respectively (34).

\section{Aplastic Anemia}

Patients with severe aplastic anemia undergo HCT as first line therapy if a MSD is available or as salvage therapy if they fail immune suppression therapy. A retrospective review of patients who failed immune suppression therapy and received MUD HCT after fludarabine, cyclophosphamide, and alemtuzumab conditioning therapy demonstrated that the majority of children achieved normal lymphocyte subsets by 12 months post HCT (35). Infectious complications included adenoviremia (2.3\%), EBV viremia (22.7\%), and CMV viremia (22.7\%) (35). Our group published a report of 17 patients undergoing HCT with alemtuzumab, fludarabine and melphalan conditioning (36). While NK cells recovered early, T cell (both CD4 and CD8) and $\mathrm{B}$ cell recovery was markedly delayed with all populations normalizing by 1 year after HCT (36). Consistent with these kinetics, infection rates were higher in the first 6 months post HCT (36).

A recent study of pediatric and adult patients (median age of 14 years) with aplastic anemia treated with haploidentical HCT utilizing busulfan, cyclophosphamide and ATG reported rapid neutrophil recovery at median of 12 days and monocyte recovery by 30 days after transplantation (37). CD8 T cell recovery

TABLE 1 | Immune reconstitution with and without conditioning for SCID.

\begin{tabular}{|c|c|c|c|c|c|c|}
\hline Genotype & Immune phenotype & Conditioning & CD8 T Cell & CD4 T Cell & B Cell & References \\
\hline \multirow[t]{2}{*}{ IL2RG/JAK3 } & $\mathrm{T}-\mathrm{B}+\mathrm{NK}-$ & No & + & + & - & $(38-42,44,45)$ \\
\hline & & Yes & + & + & + & \\
\hline \multirow[t]{2}{*}{ ADA } & T- B- NK- & No & + & + & + & \\
\hline & & Yes & + & + & + & \\
\hline \multirow[t]{2}{*}{ RAG1/2/Artemis } & T- B- NK + & No & - & - & - & \\
\hline & & Yes & + & + & + & \\
\hline \multirow[t]{2}{*}{ IL7R } & $\mathrm{T}-\mathrm{B}+\mathrm{NK}+$ & No & + & + & $+^{*}$ & \\
\hline & & Yes & + & + & + & \\
\hline
\end{tabular}

+Indicates reconstitution is likely after HCT. -Indicates unlikely to reconstitute after HCT. *Indicates recipient reconstitution aided by donor cells. 
occurred at 60 days while CD4 T cell repopulation was delayed to 1 year post $\mathrm{HCT}$, resulting in an inverted CD4:CD8 ratio during that time period (37). Interestingly, patients with a lower CD4:CD8 ratio on day 30 post HCT had higher overall survival (37). Younger recipient age, female gender, high mononuclear cell count in the graft, and absence of CMV reactivation were all independently associated with improved IR after transplant (37).

\section{Primary Immunodeficiency}

Severe combined immunodeficiencies (SCID) are a heterogeneous group of genetic disorders characterized by a lack of $\mathrm{T}$ cell progenitors available to develop within the thymus resulting in failure of $\mathrm{T}$ cell maturation as well as impaired cellular and humoral immunity (38). IR following HCT for SCID is variable based on intrinsic factors related to the underlying genetic defect (i.e., timing of developmental arrest) and modifiable factors, such as conditioning therapy (Table 1) (38-41). HCT without conditioning from an HLA-matched donor (related or unrelated) or $\mathrm{T}$ cell-depleted haploidentical donor allows successful thymopoiesis and T cell IR in SCID patients with IL2 receptor gamma chain (IL2RG), Janusassociated kinase 3 (JAK3), and adenosine deaminase (ADA) mutations (38). However, patients with IL2RG- and JAK3mutant SCID transplanted without conditioning have lower (often absent) donor stem cell engraftment and, consequently, do not have donor B cell repopulation (42). In the absence of donor B cell engraftment, patients often require lifelong immunoglobulin replacement. In contrast, patients with interleukin-7 receptor (IL7R)-deficient SCID have intact function of B cells, which can produce immunoglobulin with help from donor $\mathrm{T}$ cells (38). Notably, without donor stem cell engraftment, patients are at risk of early $\mathrm{T}$ cell exhaustion due to limited donor-derived thymopoiesis (38). In ADA-deficient SCID, the majority of patients who receive non-conditioned MRD HCT graft engraft donor stem cells and have sustained cellular and humoral IR (43). SCID patients with mutation of RAG1, RAG2 or DCLRE1C (ARTEMIS) have arrest of thymopoiesis at later developmental stages and require conditioning to achieve recovery of donor immunity (38).

A recent prospective study demonstrated that patients with SCID who received conditioning (RIC or MAC) prior to HCT had significantly higher levels of $\mathrm{T}, \mathrm{B}$, and myeloid cell donor chimerism at day 100, which persisted at 1 year post HCT (44). Furthermore, use of conditioning correlated with higher CD4 cell counts and greater likelihood of independence from immunoglobulin therapy at 1 year post HCT (44). There was no difference in overall survival based on receiving conditioning (44). While IR is improved with pre-transplant conditioning, there are significant potential toxicities and optimal conditioning therapy is still not known $(38,44)$.

In addition to conditioning, many other variables impact IR after HCT in SCID patients. HCT with an URD is associated with better $\mathrm{T}$ cell reconstitution whereas HCT with a mismatched related donor has poorer B cell reconstitution (45). IR also varies based on SCID genotype. RAG1/2 and DCLRE1C mutations have poorer $\mathrm{T}$ cell reconstitution after transplant (45). In regard to $\mathrm{B}$ cell reconstitution, in non-MSD recipients, $A D A$, $I L 7 R, C D 45$, and CD3 genotypes have a higher probability of stopping immunoglobulin replacement therapy compared to IL2RG, JAK3, RAG1/2, and DCLRE1C genotypes (45).

Regardless of genotype or conditioning, a CD4 T cell count $\geq 500$ cells/cumm at 6 and 12 months post HCT correlates with significantly better long-term overall survival (45). Furthermore, in SCID patients receiving $\mathrm{T}$ cell replete grafts, low numbers of total T cells, CD8 T cells, naive CD4 T cells, and polyclonal V $\beta$ diversity at day 100 were all linked to higher risk of death or need for a second transplant at 2 years (44).

\section{DISCUSSION}

Reconstitution of the donor-derived immune system is essential for achieving optimal outcomes for pediatric transplant recipients. The timing and extent of recovery of immune cell numbers and function directly impact infectious complications, development and treatment of GVHD, and long-term survival. Innate immunity establishes rapidly after transplant and, generally, is only modestly impacted by transplant-associated variables. In contrast, adaptive immunity recovers with highly variable kinetics that are strongly influenced by numerous factors. Indeed, the timing and characteristics of IR can be adjusted by modifiable factors, including stem cell source and dose, conditioning regimen, and use/timing of serotherapy. The establishment of donor immunity uniquely impacts the post-transplant course based on initial diagnosis and disease presentation. As such, it's critical to not only assess general patterns of IR but to evaluate these within disease-specific contexts.

Newer transplant approaches utilizing alternative donor sources, novel preparative regimens, and innovative graft manipulation strategies will invariably impact recovery of immune function. Additionally, identifying therapies that enhance IR remains an important focus of investigation. Innovative approaches include use of cytokines (IL-7 and IL-22), keratinocyte-growth factor, sex steroid ablation, and adoptive cell therapies (3, 46-51). Cellular therapies, such as viral-specific T cells, provide opportunities to support immune function while awaiting establishment of full IR. Careful evaluation of immune recovery will be essential in determining the impact of these therapeutic advances on transplant outcomes.

\section{AUTHOR CONTRIBUTIONS}

SB and JB wrote the manuscript jointly. Both authors contributed to the article and approved the submitted version.

\section{FUNDING}

JB was partially funded by an American Society of Hematology Scholar Award, a Gabrielle's Angel Foundation Award and the Children's Discovery Institute at St. Louis Children's Hospital and Washington University School of Medicine. 


\section{REFERENCES}

1. Elfeky R, Lazareva A, Qasim W, Veys P. Immune reconstitution following hematopoietic stem cell transplantation using different stem cell sources. Expert Rev Clin Immunol. (2019) 15:735-51. doi: 10.1080/1744666x.2019. 1612746

2. Mellgren K, Nierop AFM, Abrahamsson J. Use of multivariate immune reconstitution patterns to describe immune reconstitution after allogeneic stem cell transplantation in children. Biol Blood Marrow Transplant. (2019) 25:2045-53. doi: 10.1016/j.bbmt.2019.06.018

3. Chaudhry MS, Velardi E, Malard F, van den Brink MR. Immune reconstitution after allogeneic hematopoietic stem cell transplantation: time to $\mathrm{T}$ up the thymus. J Immunol. (2017) 198:40-6. doi: 10.4049/jimmunol.1601100

4. Storek J, Dawson MA, Storer B, Stevens-Ayers T, Maloney DG, Marr KA, et al. Immune reconstitution after allogeneic marrow transplantation compared with blood stem cell transplantation. Blood. (2001) 97:3380-9.

5. Renard C, Barlogis V, Mialou V, Galambrun C, Bernoux D, Goutagny MP, et al. Lymphocyte subset reconstitution after unrelated cord blood or bone marrow transplantation in children. Br J Haematol. (2011) 152:322-30. doi: 10.1111/j.1365-2141.2010.08409.x

6. Ogonek J, Kralj Juric M, Ghimire S, Varanasi PR, Holler E, Greinix $\mathrm{H}$, et al. Immune reconstitution after allogeneic hematopoietic stem cell transplantation. Front Immunol. (2016) 7:507.

7. Charrier E, Cordeiro P, Brito RM, Mezziani S, Herblot S, Le Deist F, et al. Reconstitution of maturating and regulatory lymphocyte subsets after cord blood and BMT in children. Bone Marrow Transplant. (2013) 48:376-82. doi: 10.1038/bmt.2012.176

8. Abdel-Azim H, Elshoury A, Mahadeo KM, Parkman R, Kapoor N. Humoral immune reconstitution kinetics after allogeneic hematopoietic stem cell transplantation in children: a maturation block of igm memory B cells may lead to impaired antibody immune reconstitution. Biol Blood Marrow Transplant. (2017) 23:1437-46. doi: 10.1016/j.bbmt.2017.05.005

9. Bartelink IH, Belitser SV, Knibbe CA, Danhof M, de Pagter AJ, Egberts TCG, et al. Immune reconstitution kinetics as an early predictor for mortality using various hematopoietic stem cell sources in children. Biol Blood Marrow Transplant. (2013) 19:305-13. doi: 10.1016/j.bbmt.2012.10.010

10. Lucchini G, Perales MA, Veys P. Immune reconstitution after cord blood transplantation: peculiarities, clinical implications and management strategies. Cytotherapy. (2015) 17:711-22. doi: 10.1016/j.jcyt.2015.03.614

11. Danby R, Rocha V. Improving engraftment and immune reconstitution in umbilical cord blood transplantation. Front Immunol. (2014) 5:68.

12. Young JH, Logan BR, Wu J, Wingard JR, Weisdorf DJ, Mudrick C, et al. Infections after transplantation of bone marrow or peripheral blood stem cells from unrelated donors. Biol Blood Marrow Transplant. (2016) 22:359-70.

13. Bertaina A, Merli P, Rutella S, Pagliara D, Bernardo ME, Masetti R, et al. HLA-haploidentical stem cell transplantation after removal of alphabeta+ T and B cells in children with nonmalignant disorders. Blood. (2014) 124:822-6. doi: 10.1182/blood-2014-03-563817

14. Castillo N, Garcia-Cadenas I, Barba P, Canals C, Díaz-Heredia C, Martino R, et al. Early and long-term impaired T lymphocyte immune reconstitution after cord blood transplantation with antithymocyte globulin. Biol Blood Marrow Transplant. (2017) 23:491-7. doi: 10.1016/j.bbmt.2016.11.014

15. Wagner JE Jr., Brunstein CG, Boitano AE, DeFor TE, McKenna D, Sumstad D, et al. Phase I/II Trial of StemRegenin-1 expanded umbilical cord blood hematopoietic stem cells supports testing as a stand-alone graft. Cell Stem Cell. (2016) 18:144-55. doi: 10.1016/j.stem.2015.10.004

16. Ruggeri A, Peffault de Latour R, Carmagnat M, Clave E, Douay C, Larghero J, et al. Outcomes, infections, and immune reconstitution after double cord blood transplantation in patients with high-risk hematological diseases. Transpl Infect Dis. (2011) 13:456-65. doi: 10.1111/j.1399-3062.2011. 00632.x

17. Jacobson CA, Turki AT, McDonough SM, Stevenson KE, Kim HT, Kao $\mathrm{G}$, et al. Immune reconstitution after double umbilical cord blood stem cell transplantation: comparison with unrelated peripheral blood stem cell transplantation. Biol Blood Marrow Transplant. (2012) 18:565-74. doi: 10. 1016/j.bbmt.2011.08.018

18. Horwitz ME, Wease S, Blackwell B, Valcarcel D, Frassoni F, Boelens JJ, et al. Phase I/II study of stem-cell transplantation using a single cord blood unit expanded ex vivo with nicotinamide. J Clin Oncol. (2019) 37:367-74. doi: $10.1200 /$ jco. 18.00053

19. Chiesa R, Gilmour K, Qasim W, Adams S, Worth AJJ, Zhan H, et al. Omission of in vivo T-cell depletion promotes rapid expansion of naive CD4+ cord blood lymphocytes and restores adaptive immunity within 2 months after unrelated cord blood transplant. Br J Haematol. (2012) 156:656-66. doi: 10.1111/j.13652141.2011.08994.x

20. Admiraal R, van Kesteren C, Jol-van der Zijde CM, Lankester AC, Bierings $\mathrm{MB}$, Egberts TCG, et al. Association between anti-thymocyte globulin exposure and $\mathrm{CD} 4+$ immune reconstitution in paediatric haemopoietic cell transplantation: a multicentre, retrospective pharmacodynamic cohort analysis. Lancet Haematol. (2015) 2:e194-203. doi: 10.1016/s2352-3026(15) 00045-9

21. Castillo N, Garcia-Cadenas I, Diaz-Heredia C, Martino R, Barba P, Ferrà C, et al. Cord blood units with high CD3(+) cell counts predict early lymphocyte recovery after in vivo $\mathrm{T}$ cell-depleted single cord blood transplantation. Biol Blood Marrow Transplant. (2016) 22:1073-9. doi: 10.1016/j.bbmt.2016.03.009

22. Bielorai B, Jacoby E, Varda-Bloom N, Hutt D, Churi C, Vernitsky $\mathrm{H}$, et al. Haploidentical hematopoietic stem cell transplantation with alphabetaTCR+/CD19+ depletion in pediatric patients with malignant and non-malignant disorders. Bone Marrow Transplant. (2019) 54:694-7. doi: 10.1038/s41409-019-0607-0

23. Chang YJ, Zhao XY, Huang XJ. Immune reconstitution after haploidentical hematopoietic stem cell transplantation. Biol Blood Marrow Transplant. (2014) 20:440-9. doi: 10.1016/j.bbmt.2013.11.028

24. Law J, Cowan MJ, Dvorak CC, Musick L, Long-Boyle JR, Baxter-Lowe LA, et al. Busulfan, fludarabine, and alemtuzumab as a reduced toxicity regimen for children with malignant and nonmalignant diseases improves engraftment and graft-versus-host disease without delaying immune reconstitution. Biol Blood Marrow Transplant. (2012) 18:1656-63. doi: 10.1016/j.bbmt.2012.05. 006

25. Marsh RA, Rao MB, Gefen A, Bellman D, Mehta PA, Khandelwal P, et al. Experience with alemtuzumab, fludarabine, and melphalan reducedintensity conditioning hematopoietic cell transplantation in patients with nonmalignant diseases reveals good outcomes and that the risk of mixed chimerism depends on underlying disease, stem cell source, and alemtuzumab regimen. Biol Blood Marrow Transplant. (2015) 21:1460-70. doi: 10.1016/j. bbmt.2015.04.009

26. Bhatt ST, Bednarski JJ, Berg J, Trinkaus K, Murray L, Hayashi R, et al. Immune reconstitution and infection patterns after early alemtuzumab and reduced intensity transplantation for nonmalignant disorders in pediatric patients. Biol Blood Marrow Transplant. (2019) 25:556-61. doi: 10.1016/j.bbmt.2018.10.008

27. Kottaridis PD, Milligan DW, Chopra R, Chakraverty RK, Chakrabarti S, Robinson S, et al. In vivo CAMPATH-1H prevents graft-versus-host disease following nonmyeloablative stem cell transplantation. Blood. (2000) 96:241925. doi: 10.1182/blood.v96.7.2419.h8002419_2419_2425

28. Shenoy S, Grossman WJ, DiPersio J, Yu LC, Wilson D, Barnes YJ, et al. A novel reduced-intensity stem cell transplant regimen for nonmalignant disorders. Bone Marrow Transplant. (2005) 35:345-52. doi: 10.1038/sj.bmt.1704795

29. Marsh RA, Kim MO, Liu C, Davies SM, Jordan MB, Filipovich AH, et al. An intermediate alemtuzumab schedule reduces the incidence of mixed chimerism following reduced-intensity conditioning hematopoietic cell transplantation for hemophagocytic lymphohistiocytosis. Biol Blood Marrow Transplant. (2013) 19:1625-31. doi: 10.1016/j.bbmt.2013.09.001

30. Marsh RA, Lane A, Mehta PA, Neumeier L, Jodele S, Davies SM, et al. Alemtuzumab levels impact acute GVHD, mixed chimerism, and lymphocyte recovery following alemtuzumab, fludarabine, and melphalan RIC HCT. Blood.(2016) 127:503-12. doi: 10.1182/blood-2015-07-659672

31. Rajasekar R, Mathews V, Lakshmi KM, George B, Viswabandya A, Chandy $\mathrm{M}$, et al. Cellular immune reconstitution and its impact on clinical outcome in children with beta thalassemia major undergoing a matched related myeloablative allogeneic bone marrow transplant. Biol Blood Marrow Transplant. (2009) 15:597-609. doi: 10.1016/j.bbmt.2009.01.016

32. Goussetis E, Efstathiou E, Paisiou A, Avgerinou G, Zisaki K, Giamouris VJ, et al. Infectious complications following allogeneic stem cell transplantation by using anti-thymocyte globulin-based myeloablative conditioning regimens in children with hemoglobinopathies. Transpl Infect Dis. (2015) 17:201-7. doi: $10.1111 /$ tid. 12358 
33. Qin F, Shi L, Li Q, Zhang Z, Liu L, Li J, et al. Immune recovery after in vivo T-cell depletion myeloablative conditioning hematopoietic stem cell transplantation in severe beta-thalassemia children. Eur J Haematol. (2019) 103:342-50. doi: 10.1111/ejh.13289

34. King AA, Kamani N, Bunin N, Sahdev I, Sahdev J, Brochstein J, et al. Successful matched sibling donor marrow transplantation following reduced intensity conditioning in children with hemoglobinopathies. Am J Hematol. (2015) 90:1093-8. doi: 10.1002/ajh.24183

35. Samarasinghe S, Steward C, Hiwarkar P, Saif MA, Hough R, Webb D, et al. Excellent outcome of matched unrelated donor transplantation in paediatric aplastic anaemia following failure with immunosuppressive therapy: a United Kingdom multicentre retrospective experience. Br J Haematol. (2012) 157:339-46. doi: 10.1111/j.1365-2141.2012. 09066.x

36. Ngwube A, Hayashi RJ, Murray L, Loechelt B, Dalal J, Jaroscak J, et al. Alemtuzumab based reduced intensity transplantation for pediatric severe aplastic anemia. Pediatr Blood Cancer. (2015) 62:1270-6. doi: 10.1002/pbc. 25458

37. Pei XY, Zhao XY, Xu LP, Wang Y, Zhang X-H, Chang Y-J, et al. Immune reconstitution in patients with acquired severe aplastic anemia after haploidentical stem cell transplantation. Bone Marrow Transplant. (2017) 52:1556-62. doi: 10.1038/bmt.2017.174

38. Gennery AR, Lankester A. Long term outcome and immune function after hematopoietic stem cell transplantation for primary immunodeficiency. Front Pediatr. (2019) 7:381.

39. Laberko A, Gennery AR. Cytoreductive conditioning for severe combined immunodeficiency-help or hindrance? Expert Rev Clin Immunol. (2015) 11:785-8. doi: 10.1586/1744666x.2015.1041926

40. Dvorak CC, Patel K, Puck JM, Wahlstrom J, Dorsey MJ, Adams R, et al. Unconditioned unrelated donor bone marrow transplantation for IL7R $\alpha$ - and Artemis-deficient SCID. Bone Marrow Transplant. (2017) 52:1036-8. doi: 10.1038/bmt.2017.74

41. Castagnoli R, Delmonte OM, Calzoni E, Notarangelo LD. Hematopoietic stem cell transplantation in primary immunodeficiency diseases: current status and future perspectives. Front Pediatr. (2019) 7:295.

42. Pai SY, Logan BR, Griffith LM, Buckley RH, Parrott RE, Dvorak CC, et al. Transplantation outcomes for severe combined immunodeficiency, 20002009. N Engl J Med. (2014) 371:434-46.

43. Hassan A, Booth C, Brightwell A, Allwood Z, Veys P, Rao K, et al. Outcome of hematopoietic stem cell transplantation for adenosine deaminase-deficient severe combined immunodeficiency. Blood. (2012) 120:3615-24; quiz 3626.
44. Heimall J, Logan BR, Cowan MJ, Notarangelo LD, Griffith LM, Puck JM, et al. Immune reconstitution and survival of 100 SCID patients post-hematopoietic cell transplant: a PIDTC natural history study. Blood. (2017) 130:2718-27. doi: 10.1182/blood-2017-05-781849

45. Haddad E, Logan BR, Griffith LM, Buckley RH, Parrott RE, Prockop SE, et al. SCID genotype and 6-month posttransplant CD4 count predict survival and immune recovery. Blood. (2018) 132:1737-49.

46. Zakrzewski JL, Kochman AA, Lu SX, Terwey H, Kim TD, Hubbard VM, et al. Adoptive transfer of T-cell precursors enhances T-cell reconstitution after allogeneic hematopoietic stem cell transplantation. Nat Med. (2006) 12:1039-47.

47. Zhang P, Tey SK. Adoptive $\mathrm{T}$ cell therapy following haploidentical hematopoietic stem cell transplantation. Front Immunol. (2019) 10:1854.

48. Perales MA, Goldberg JD, Yuan J, Koehne G, Lechner L, Papadopoulos EB, et al. Recombinant human interleukin-7 (CYT107) promotes T-cell recovery after allogeneic stem cell transplantation. Blood. (2012) 120:4882-91. doi: 10.1182/blood-2012-06-437236

49. Dudakov JA, Hanash AM, Jenq RR, Young LF, Ghosh A, Singer NV, et al. Interleukin-22 drives endogenous thymic regeneration in mice. Science. (2012) 336:91-5. doi: 10.1126/science.1218004

50. Sutherland JS, Spyroglou L, Muirhead JL, Heng TS, Prieto-Hinojosa A, Prince $\mathrm{HM}$, et al. Enhanced immune system regeneration in humans following allogeneic or autologous hemopoietic stem cell transplantation by temporary sex steroid blockade. Clin Cancer Res. (2008) 14:1138-49. doi: 10.1158/10780432.ccr-07-1784

51. Wils EJ, Aerts-Kaya FS, Rombouts EJ, Van Mourik I, Rijken-Schelen A, Visser TP, et al. Keratinocyte growth factor and stem cell factor to improve thymopoiesis after autologous CD34+ cell transplantation in rhesus macaques. Biol Blood Marrow Transplant. (2012) 18:55-65. doi: 10.1016/j.bbmt.2011. 09.010

Conflict of Interest: The authors declare that the research was conducted in the absence of any commercial or financial relationships that could be construed as a potential conflict of interest.

Copyright (c) 2020 Bhatt and Bednarski. This is an open-access article distributed under the terms of the Creative Commons Attribution License (CC BY). The use, distribution or reproduction in other forums is permitted, provided the original author(s) and the copyright owner(s) are credited and that the original publication in this journal is cited, in accordance with accepted academic practice. No use, distribution or reproduction is permitted which does not comply with these terms. 